\title{
Prólogo
}

\section{Capitalismo tardío y sujetos transformadores. Análisis y perspectivas}

\section{Andrés Piqueras, María Emilia Tijoux y Antonio Elizalde}

El capitalismo histórico ha experimentado, en la escala mundial que hoy le corresponde, profundos cambios que han modificado sustancialmente su componente de acumulación, pero también, de forma significativa, el de regulación, perturbando críticamente su forma de gestionar las inequidades, desigualdades y doxas que él mismo produce. Actualmente, la expansión de un capitalismo autoritario premunido del paradigma mercantil, promueve una cultura individual que ha calado duramente en los sujetos y en los movimientos transformadores de la sociedad, dejándolos sometidos a un nuevo orden/desorden. Las solidaridades colectivas del campo laboral se han fragmentado obligando a los trabajadores a una competitividad que mella sobre la fuerza de sus organizaciones y que afecta las confianzas necesarias para resistir al embate de los poderosos.

Las relaciones sociales de producción contienen relaciones sociales del trabajo que transforman a los trabajadores en cesantes, en precarios, o en trabajadores clandestinos e ilegales cada vez más disponibles como fuerza de trabajo migrante global. A estas situaciones se agrega la permanente desigualdad entre hombres y mujeres, que deja a éstas en un lugar subordinado a causa de la constante reproducción del trabajo doméstico. El sistema familiar de los hogares más pobres deviene un complejo y desconocido sistema de subsistencia laboral, y los niños, hijos e hijas de los trabajadores precarios, dejan de ser sujetos de cuidado, pues su niñez desaparece entre distintas labores que prematuramente les exige proveer económicamente al sustento del hogar, o realizar un trabajo doméstico repleto de funciones que antes desempeñaban los adultos.

Estas nuevas situaciones de miseria desplazan a la pobreza hasta reducirla a una pura categoría productora de políticas públicas que flotan sin destino, pero van mostrando al mismo tiempo que la lucha por la subsistencia es el centro de las preocupaciones. Ante este panorama, los actores luchan en diversos sectores por sobrevivir y desde distintos grupos que protestan por situaciones específicas o que promueven nuevos modos de enfrentar la precariedad que los caracteriza. Pero aún en estas condiciones, las razones de sus luchas siguen siendo las mismas que levantaran los actores de los movimientos sociales que en el llamado "corto siglo XX" tejían proyectos de emancipación y de justicia. 
América Latina ha vivido en las últimas décadas una experiencia neoliberal que se ha desencadenado en casi todos los países. La concentración de la riqueza esgrimida como triunfo económico ha hecho estragos. La destructiva lógica del capital parece haber llegado a su punto más feroz gracias a la retirada de los Estados, al servilismo generalizado de los gobiernos y a las transnacionalizaciones protagonizadas por las burguesías de cada país, cada vez más abultadas de un poder que las obliga a defender a cualquier precio sus propiedades de los posibles ataques de estas "clases peligrosas”. Al sentirse inseguras, esgrimirán la delincuencia de los pobres como el principal enemigo de sus democracias y ella será el tópico dominante de discursos electorales que actúan para la fabricación generalizada del temor en una denominada “opinión pública” que justifica el encierro en las cárceles que no dan abasto, tal como ocurre en Chile que ostenta la cifra más alta de personas encarceladas en el continente.

Claramente el Estado nacional, funcionando puertas abiertas a las grandes firmas en un contexto de mundialización y preocupado por atraer capitales en las mejores condiciones posibles, precisa enfrentar los problemas sociales de manera jurídico-penal, y para ello criminaliza a los sectores más vulnerables (sin duda el negocio es redondo, pues a mayor número de gente presa, mayor ganancia).

La combatividad explícita del Trabajo, desde que se constituye como sujeto histórico, ha experimentado una alta discontinuidad o momentos de auge y decadencia que ciertas escuelas de la ciencia social han intentado explicar e incluso secuenciar en virtud de diferentes criterios. Una de las más potentes líneas de explicación sobre esa discontinuidad del accionar político del Trabajo es la que ha vinculado éste a las recurrentes crisis estructurales del capitalismo y las correspondientes estrategias del Capital para sobreponerse a las mismas.

De este esfuerzo analítico se deriva la formulación del concepto de ondas largas, que hacen referencia a periodos de ascendencia y descendencia de la acumulación capitalista. En las ondas ascendentes de acumulación del Sistema estos procesos se contrarrestan por un tiempo, el Capital es capaz, y así lo ha mostrado históricamente, de aumentar los niveles de vida del Trabajo mediante la elevación general de la productividad y de la riqueza total generada en una sociedad mediante el desarrollo acelerado de las fuerzas productivas (esto es, con el incremento de los medios de producción, más la elevación de la cualificación, oportunidades y demandas de vida de los seres humanos).

En esas circunstancias, el Capital es más proclive a aceptar incrementar la distribución de la ganancia en forma de salarios directos e indirectos, por lo que las reivindicaciones del Trabajo encuentran un territorio menos hostil, que no fácil. Hecho que hace incrementar, por su parte, la conciencia reformista del Trabajo, o la creencia en la negociación y, en general, en las vías institucionales para ir obteniendo mejoras continuas, de manera que la elevación de la calidad de vida com- 
pense, para muchos, los esfuerzos laborales (los cuales incluso pueden verse también rebajados debido al ascenso de la productividad). En esos momentos históricos el capitalismo parece un sistema beneficioso o de suma 1 positiva: todos ganan con él (aunque sea en desigual proporción).

Se produce por tanto, en estas fases, una inclinación a una parcial desmercantilización de la fuerza de trabajo. Con ello, a través del tiempo, se acrecienta el poder social de negociación del Trabajo y tiende a disminuir la rentabilidad general del capital.

En las subsecuentes fases descendentes se desata un mayor descontento pero al tiempo disminución del poder social de negociación del Trabajo, que van de la mano de mayores niveles de represión y conflicto. Se incrementa la mercantilización de la fuerza de trabajo y diferentes combinaciones de conflictividad del Trabajo, que se hace más generalizada.

La premisa general es que cualquier salida hacia adelante en orden a superar una de sus fases de crisis requiere para el Capital una ofensiva general contra el Trabajo y sus logros históricos, para recomponer tanto la tasa de ganancia como el poder de clase (al que aquélla está ligada fundamentalmente).

No obstante, tales procesos no son ineluctables; las escuelas y enfoques teóricos que ponen su hincapié en la agencialidad humana, insisten en que las tendencias anunciadas quedan siempre supeditadas al propio desarrollo del Trabajo como sujeto en cada fase histórica, así como a sus plasmaciones organizativas e ideológicas. Factores que tampoco son independientes de la propia evolución del sistema capitalista y de la conformación del Capital como sujeto histórico. Unos y otros procesos están entrelazados dialécticamente.

Uno de los desafíos intelectuales y sobre todo políticos del momento actual es explicar las razones por las cuales si el movimiento obrero tuvo un gran respaldo popular o comunitario más allá de los centros laborales, en los momentos de resistencia generalizada, cuando el Trabajo se rehacía de la dureza de la agresión de clase en las fases descendentes de la acumulación de capital, hoy esto no se da. En qué medida y por qué se produce la drástica decadencia política de la fuerza de trabajo y también la dilución general de las fuerzas del Trabajo, no son procesos solamente a explicar, sino también a intentar revertir desde el compromiso militante de la ciencia.

Pero reflexionar desde el compromiso de clase por parte de los científicos sociales requiere de una rigurosa tarea de recuperación y sistematización de la memoria histórica de las luchas y los logros del Trabajo, sin la cual las luchas del presente se deshilachan, huérfanas de una óptica y una estrategia más holísticas, en una aparente multitud de resistencias tan esporádicas como inconexas. 
Numerosas circunstancias, sin embargo, han llevado a desplazar el interés académico hacia otros conflictos o procesos pretendidamente "postmodernos", a menudo asociados a los que fueron llamados "nuevos movimientos sociales”, copiando en demasía criterios y elementos de análisis de la ciencia dominante.

En consecuencia, ha sido un lugar común en buena parte de la elaboración académica de al menos las últimas dos décadas asegurar que las luchas del Trabajo han quedado en un segundo plano frente a otros sujetos, como las clases medias radicalizadas, las adscripciones étnicas, los pueblos, las mujeres, los jóvenes, los excluidos, etc. De forma que si antes el movimiento obrero fue el sujeto antagónico por excelencia y nadie cuestionaba que protagonizaba la conducción de lo popular, hoy se hace ver justamente lo contrario, que lo "obrero" como expresión de lo proletario salarizado se subsume en la heteroclitud multiforme de "lo popular”, diluyéndose con ello también la posibilidad de encontrar un "sujeto-vanguardia”.

Pero si miramos las cosas desde otra perspectiva y entendemos que unos y otros de estos pretendidos "nuevos" sujetos no son sino expresiones del Trabajo, en cuanto que Trabajo generizado, etnificado o racificado, cualificado, generacional, etc., que cobran autonomía e importancia propia como sujetos antagónicos al Capital, las preguntas a plantearse y a resolver muy probablemente han de ser otras.

Frente a un panorama como éste: ¿Qué pueden hacer los sujetos? ¿De qué modo resisten a la existencia cotidiana? ¿Cuáles son y cómo son sus luchas? ¿Podríamos llamarlos movimientos sociales? ¿Qué dicen quienes debaten a este propósito? ¿Se inaugurará una nueva ola de conflictos con potencialidad transformadora en la fase decadente del capitalismo tardío? ¿Coincidirán las nuevas formas de insubordinación desencadenadas por el despojo con las que suscita la sobreexplotación? ¿Confluirán por fin las diferentes identidades precapitalistas y las que han irrumpido de las fracturas al interior del propio Trabajo, como las de género, en un reforzamiento mutuo con las identidades de clase? Estas son algunas de las preguntas o claves, ineludibles para la construcción de posibles futuros alternativos, que Polis quiere afrontar en el presente número. Son los ejes sobre los que giran las aportaciones que en él se incluyen.

La convocatoria para el Lente de aproximación fue notablemente exitosa pues permitió reunir un conjunto de trabajos que desde diversas perspectivas fue proporcionando claves interpretativas que nos permiten dar cuenta de algunas de las interrogantes que dieron origen a este número; es así como Mariana Barattini en su artículo "El trabajo precario en la era de la globalización. ¿Es posible la organización?” presenta la experiencia de la Coordinadora de Trabajadores/as Precarizadas/os que reúne a trabajadores ligados a los nuevos servicios de la economía quienes se propusieron problematizar su condición de transitoriedad y alta rotación, en donde la condición laboral del trabajador aparece individualizada y 
despolitizada, pues son proveedores de servicios con obligaciones y no trabajadores con derechos, situación que los desvincula de los marcos reguladores tradicionales de las relaciones laborales y genera un obstáculo a las posibilidades de organización alternativa como forma de modificar la situación de precariedad y de construir una identidad común de trabajadores en ese mundo laboral fragmentado y precarizado donde desarrollan su actividad. Indaga además la posibilidad de generar procesos organizativos partiendo de esa condición.

“Sobre-tiempo de trabajo en Chile: Un modelo exploratorio" se titula el trabajo de Jan Cademartori, Daniel Cáceres y Alfredo Vásquez quienes identifican algunos factores que inciden en el tiempo de trabajo de los trabajadores chilenos en 2003. Concluyen que la precariedad laboral influye de modo significativo en las horas trabajadas, si bien la relación cambia a partir de cierto nivel cuando las personas no pueden trabajar la jornada por falta de oportunidades. Ello sugiere que el sobre-trabajo y el sub-empleo son manifestaciones del mismo fenómeno, por lo cual nuevas medidas para aumentar los derechos patronales agravarían estos problemas. Asimismo, se devela una relación negativa entre salario por hora y horas trabajadas para cerca del $80 \%$ de los trabajadores. Esto hace pensar que las necesidades básicas están insatisfechas; además contradice la porción significativa de la curva de oferta laboral de los libros de texto de microeconomía. Estas relaciones se confirman en un modelo exploratorio añadiendo variables de control de tipo regional, demográfico y productivo.

François Chesnais titula "Un año después del crack bancario y financiero. En todos los países una situación muy difícil para los trabajadores y los oprimidos y a escala planetaria una fase crítica para la civilización humana” el artículo en el cual aborda la crisis financiera analizando tanto sus orígenes como las profundidades de su implementación. Aunque algunos Estados aseguran haberla superado dicha crisis no se ha terminado y sus consecuencias tocan a las distintas esferas de la vida social dañando de ese modo a los individuos como a las relaciones sociales que son indispensables para la solidaridad entre las sociedades y al interior de las sociedades mismas. Chesnais nos invita a reflexionar sobre un problema que precisa ser pensado y resuelto a partir de un esfuerzo combinado entre todos los ciudadanos de un mundo cada vez más sometido a la dominación de capitalistas enceguecidos por la sed de ganancia que les impide ver que genera su propia destrucción.

Bruno Fornillo presenta en "Proletariado minero, nacionalización económica y el reposicionamiento actual de la Central Obrera Boliviana" un trabajo realizado principalmente en base a fuentes primarias, que procura dar cuenta del transito del sector obrero minero Boliviano -núcleo proletario central del siglo pasado- desde la aplicación de las reformas estructurales del año 85, cuando se cierran las principales minas estatales, a la actualidad. Durante el “evismo”, la acción colectiva del sector minero fue central para forzar la nacionalización de la principal reserva estañífera del país, trayendo consigo una nueva elite de gestión ministerial en el área. Describe 
también el recorrido trazado en tiempos recientes por la antes fortísima Central Obrera Boliviana. Su carácter opositor en relación con los gobiernos neoliberales encontró una línea de continuidad para con la actual gestión de gobierno. Sin embargo, esta perspectiva no ha sido la dominante, por primera vez en su historia el ente matriz de los trabajadores se ha subordinado al campo de articulación popular comandado por el indigenismo.

En "Localización geohistórica de los feminismos latinoamericanos”, Doris Lamus Canavae retoma argumentos y categorías del discurso que critica el "eurocentrismo del feminismo latinoamericano" para llamar la atención sobre las elusiones o generalizaciones en que incurre. Sin desconocer los innegables orígenes del pensamiento feminista, el artículo insiste en las particularidades de los feminismos latinoamericanos, en su localización neohistórica. Con este propósito narra los avatares de la movilización feminista de los años setenta-ochenta en la región.

\section{Sandra Leiva Gómez en su artículo "La subcontratación en la mi-} nería en Chile: elementos teóricos para el análisis” analiza la subcontratación en la minería en Chile, entregando antecedentes teóricos y empíricos que permiten explicar las huelgas que han protagonizado en los últimos años los trabajadores subcontratados de la gran minería revelando. Señala la pérdida de centralidad del trabajo asalariado y el consiguiente aumento de formas de empleo atípicas. La empiria indica por otro lado un alto porcentaje de trabajadores en régimen de subcontratación en la minería. Identifica la existencia de situaciones de encubrimiento laboral conducentes a la creación de trabajadores de primera y segunda categoría, cuestión rechazada por los trabajadores subcontratados que aspiran a obtener los mismos derechos y privilegios que sus pares contratados, pues realizan exactamente el mismo tipo de trabajo.

“¿De Política de Representación a Política de Coalición? Posibilidades de Movilización Feminista en el Chile Post-Dictadura” es el trabajo de Claudia Mora y Marcela Ríos, quienes recorriendo la historia del movimiento feminista chileno demuestran que independientemente de la permanencia de condiciones de desigualdad de género en el tiempo, la acción colectiva emerge con la apertura de la estructura de oportunidades y la agencia de un grupo articulado de activistas. Los movimientos de mujeres en Chile han surgido en el marco de estas condiciones, disolviéndose luego de la consecución del propósito unificador. Un análisis de la fragmentación de los movimientos de mujeres post-dictadura indica la necesidad de atender al problema que plantea para los movimientos sociales el forjamiento de una identidad que represente al grupo. Afirman que una política de representación debe dar paso a una política de coalición, no sólo por sus posibilidades democráticas, sino que también porque en el nuevo marco socio-cultural, la conformación de coaliciones en torno a demandas de género es la vía más efectiva hacia la transformación del orden de género.

José Sanchez Parga en "Democracia caudillista y desmovilizaciones sociales en Ecuador" muestra como los conflictos y reivindicacio- 
nes de los movimientos sociales, políticamente representables, durante la transición democrática de los 80 en Ecuador, entran en crisis con el modelo de acumulación y concentración de riqueza, inaugurado por la dominación neoliberal durante los 90, dando lugar al ciclo de movilizaciones protestarias, que agravan la crisis de todo el sistema de representación política (elecciones, partidos, congreso), el que degenera en un fenómeno nuevo: el representativismo político. El imperativo de "gobernabilidad” de la protesta, la acumulación y concentración de poderes ejecutivos, para un mejor gobierno económico de la política, reforzaron los poderes del hiperpresidencialismo y la formación de una democracia caudillista, que en Ecuador adoptó una orientación contra-neoliberal.

Tito Tricot, en el ensayo titulado "El nuevo movimiento mapuche: hacia la (re) construcción del Mundo y País mapuche” analiza los conceptos y praxis del Mundo Mapuche y del País Mapuche, las cuales constituyen la síntesis de la demanda y propuesta de parte significativa del movimiento mapuche autonomista. Síntesis que conlleva una modificación cualitativa en la estructuración de los marcos cognitivos del movimiento que ha significado la articulación embrionaria de una visión mapuche de la realidad que trascendería la dimensión social y política del movimiento para instalarse como elemento de índole más estructural, que ya no sólo enfrenta crecientemente a dos identidades distintas, sino que a dos proyectos de sociedad, a dos pueblos encapsulados en un mismo territorio geográfico, pero culturalmente diferenciados.

“Sobre procesos de autogestión y recolectivización laboral en la Argentina actual” titula su artículo Gabriela Wyczykier, presentando una caracterización del proceso de autogestión laboral ocurrido en la Argentina en el período 1990-2006, apuntando especialmente sobre el universo de las Empresas Recuperadas por sus Trabajadores. Construye su argumento sobre una serie de dimensiones analíticas que singularizan a este proceso con referencia a otras experiencias autogestionarias ocurridas antecedentemente. Su singularidad descansa específicamente en que estas experiencias pueden ser estudiadas como procesos de recolectivización laboral, cuya emergencia y desarrollo se ubica en un escenario atravesado por un profundo proceso de descolectivización social, económica y política. Destaca como elementos interpretativos: la reconstrucción de un espacio y una experiencia colectiva de trabajo que recuperó parte de la historia asalariada de los trabajadores; la reconfiguración de vínculos de sociabilidad al interior del espacio productivo; y la relación con organizaciones sociales y gremiales que representaron los intereses de los trabajadores de estas empresas recuperadas.

La sección Cartografías para el futuro presenta un extenso artículo de Andrés Piqueras titulado “Ácumulación, regulación, ondas y estrategias en las luchas del trabajo” en el cual trata de realizar una introducción diacrónica de las relaciones Capital/Trabajo, con epicentro de referencia en las sociedades centrales, combinando las aportaciones de ciertas escuelas regulacionistas con las de las ondas largas del capitalismo y las 
que incluyen ciclos de combatividad del Trabajo y ofensivas o contraofensivas estratégicas del Capital, desde la estrategia investigadora del materialismo dialéctico. Su fin es servir de apoyo a modelos analíticos sobre la combatividad del Trabajo combinada con las dinámicas de acumulación y regulación del Capital, que sean capaces de vislumbrar las posibilidades de reconstitución de la agencialidad política del Trabajo en la actualidad, y acompañarlas.

La sección Proyectos y avances de investigación incluye los trabajos de Jorge Brower "Claves epistemológicas para abordar la investigación en el ámbito de la comunicación social”; de Eduardo Chávez Molina “Aportes conceptuales sobre las prácticas sociales en la feria callejera. El tema de la confianza social”; de Alberto Díaz Araya y Rodrigo Ruz Zagal "Estado, escuela chilena y población andina en la ex Subdelegación de Putre. Acciones y reacciones durante el período post Guerra del Pacífico (1883 - 1929)”; de Andrés Roldán Tonioni “Prácticas comunitarias del desarrollo: Una mirada desde los oficios y el trabajo"; y de María Evelinda Santiago Jiménez "Sustentabilidad a dos tiempos".

La sección Bosquejos para una nueva episteme contiene un interesante aporte teórico de Carlos Eduardo Martins sobre “La Teoría de la Coyuntura y la Crisis Contemporánea” en el cual propone en su primera parte la construcción de una teoría de la coyuntura a partir de la articulación de los enfoques de sistema mundial, de la dependencia y de la revolución científico-técnica; y cuya segunda parte se dedica la aplicación de este enfoque para el análisis de la crisis del 2008-10 y sus desdoblamientos en la década que se inicia.

Concluye el número con la sección Reseñas y comentarios de libros presentando las reseñas de María Esther Arancibia del libro Encantador era mi barrio de Fidias López; la de César Cuadra sobre el libro Pensar de nuevo de María Teresa Pozzoli; la reseña hecha por Maximiliano Gracia Hernández y Elva Vázquez Pérez de la obra ¿Adónde va China? de Jean-Luc Domenach, finalizando la sección con la reseña de Diana Luque sobre el libro de Enrique Leff Discursos sustentables. 